KANG, K. S. (2001): Genetic gain and gene diversity of seed orchard crops. Ph. D. dissertation. ISSN 1401-6230, ISBN 91-576-6071-9

Krusche, D., B. L. DAS and B. R. Stephan (1980): Results of a progeny test with Pinus sylvestris and estimation of genetic gains from different selection methods. Silvae Genetica 29(3-4): 122-129.

LindGren, D., L. D. GeA and P. A. Jefferson (1996): Loss of genetic diversity monitored by status number. Silvae Genetica 45: 52-59.

LINDGREN D. (2000): Low-intensity tree breeding, pp. 37-48 in Rapid generation turnover into the breeding population and low-intensity breeding, edited by $\mathrm{K}$. LUNDKVIST, Research Notes 55, Department of Forest Genetics, Uppsala, SLU, Sweden. ISSN = 0348-565X.

LINDGREN, D. (2003): Low-input tree breeding strategies. In: Eucalyptus Plantations - Research, Management and Development, R.-P. WEI and D. XU (eds), World Scientific, Singapore, 149-166.

MATHESON, A. C. and C. A. RAYMOND (1984): Effects of thinning in progeny test on estimates of genetic parameters in Pinus radiata. Silvae Genetica 33(4-5): $125-128$.
PERSSON, T. (1999): Svenska plusträdskloner från 1980 års plusträdsurval till förädlingspopulations Tpop 7 . Avelsvärden 68. SkogForsk. S-751 83 UPPSALA, Sweden.

SorEnsen, F. C. (1997): Effects of sib mating and wind pollination on nursery seedling size, growth components, and phenology of Douglas-fir seed-orchard progenies. Can. J. For. Res. 27(4): 557-566.

Squillace, A. E., J. G. A. La Bastide and C. L. H. VAN VREDENBURCH (1975): Genetic variation and breeding of Scots Pine in the Netherlands. For. Sci. 21(4): 341-352.

Varghese, M., N. Ravi, S.-G. Son and D. LindGREN (2003): Variation in fertility and its impact on gene diversity in a seedling seed orchard of Eucalyptus tereticornis, pp. 46-60 in Proceedings from Symposium on Eucalyptus plantations, Sept 1-6, 2002, Guangdong, China.

Wu, H. X., A. C. Matheson and D. Spencer (1998): Inbreeding in Pinus radiata. I. The effect of inbreeding on growth, survival and variance. Theor. Appl. Genet. 97(8): 1256-1268.

\title{
Cone Yield Characterization of a Stone Pine (Pinus pinea L.) Clone Bank
}

\author{
By S. MUtKE ${ }^{\text {a) }}$, J. GoRDo ${ }^{\text {b) }}$ and L. GIL ${ }^{\text {a),*) }}$
}

(Received $11^{\text {th }}$ April 2005)

\begin{abstract}
In spite of the use of the edible kernels of Stone pine (Pinus pinea L.) gathered from Mediterranean pine forests, the species remains a genuine forest tree that has never been domesticated as an orchard crop. In the last decades, some efforts have been made to select valuable genotypes for exploring the possibilities of Stone pine as an orchard crop. The present paper characterizes the cone yield of a grafted clone bank in order to elucidate the relevance of genetic and environment factors for seed-yield quantity and quality and for sequential transition rates of the development from pollinated conelets to ripe cones. Individual tree size and cone yield were separated in their genetic and environmental components, in order to estimate phenotypic, genetic and environmental correlations. A statistical model for logtransformed individual cone yield was adjusted, ranking the tested genotypes by their estimated clonal value after adjustment for tree size covariables. The degree of genetic determination for adjusted cone yield was esti-

a) ETSI Montes, Universidad Politécnica de Madrid (Spain).

b) Servicio Territorial de Medio Ambiente, Junta de Castilla y León.

*) Prof. Dr. Luis Gil, ETSI Montes, Universidad Politécnica de Madrid, Ciudad Universitaria, E-28040 Madrid (Spain).

Tel.: (+34) 91336 5039, Fax: (+34) 91 3366386, E-mail: lgil@montes.upm.es
\end{abstract}

mated in $15 \%$, the expected genetic gain by selection of the top $10 \%$ of tested genotypes would be $12 \%$. Genetic correlation between genetic values for cone yield and cone and seed size were weak but significantly positive ( $r=0.27$ and 0.17 ), hence the lack of trade-offs between crop quantity and quality will allow a combined selection.

Key words: Mediterranean stone pine, pine nuts, cone survival, degree of genetic determination.

\section{Introduction}

Since the Palaeolithic period, humans have gathered the cones of the Mediterranean Stone pine for their large edible kernels (GIL, 1999; BADAL, 2001). Scattered populations of the species range all over the Mediterranean countries, though the most extensive native forests grow in the Iberian Peninsula (THIRGOOD, 1981; PRADA et al., 1997). Despite of its interest as a nut tree, Stone pine has never been domesticated but remains a genuine forest tree and the cone yield is gathered from forest stands. About $70 \%$ of the world production comes from Spain and Portugal. At present, pine nuts are in increasing demand on the international market due to their delicate flavour and high nutritional value with $30 \%$ proteins and $50 \%$ fats, more than $80 \%$ of them 
unsaturated essential fatty acids (LANNER, 1981; WOLFF and BAYARD, 1995).

In the last fifty years some efforts have been made in several Mediterranean countries to install experimental plantations in order to explore the suitability of pine nuts as an orchard crop, yet little information about seed production in clonal Stone pine plantations has been published (MAGINI and GIANNINI, 1971; PrADA et al., 1997). In Spain, the few existing grafted plantations older than fifteen years were set up by forest services with mixtures of scions obtained by mass-selection; experimental clonal orchards have been established only since early Nineties (CATALÁN, 1998; CANDELA and AlÍA, 2000). Given the lack of published data about Stone pine as an orchard crop, experiences from forest seed orchards of other conifers may give some hints (cf. CHALUPKA, 1987), especially the direct correlation of the cone production with tree size due to classical scale effects (FALCONER and MACKAY, 1996; KJÆR and WELLENDORF, 1997). Nevertheless, in forest seed orchards the evaluation of the clonal contribution to seed crop aims to characterise the genetic diversity of the forest reproductive material obtained each year, for guaranteeing a balanced genetic composition of the future forests. The relevant variable is therefore the effective contribution of each clone to the annual crop, whereas correlations between clonal values for seed abundance estimated in different years are frequently low due to the presence of asymmetric annual yield variation among trees (MATZIRIS, 1993; NiKKANEN and Ruotsalainen, 2000). As a consequence, the annual estimations of the degree of genetic determination $\mathrm{H}^{2}$ are not various repeated measurements for a broad-sense 'heritability' of seed production as a character of the seed orchard, but only singular values for different crops. Also the annual estimations of genetic values do not characterize any stable trait of the genotypes or even a heritable one to their offspring. In the case of Stone pine as nut tree, on the contrary, the seed yield is the main clonal selection criterion, and the neat characterization of tested genotypes requires a major effort to obtain a unique, unbiased estimation of their genetic values for seed production.

The thirteen-year-old clone bank analysed in the present paper is one of the oldest well-documented grafted plantations in Spain, established as an ex-situ field gene bank for scion supply (MUTKE et al., 2000). It was planted at the upper altitudinal and northern limit of natural Stone pine growth area in Inner Spain, in order to provide scions with a delayed spring phenology that improves the graft-take success on rootstocks in nurseries at lower altitude, i.e. with more advanced phenostage that favour a callus formation before the scion's flush. As a consequence of this extreme location, we observed during more than a decade of orchard management that the annual growth and cone yield of the grafted trees, which are not watered, showed a direct response to annual weather conditions. This is in accordance with general behaviour of Stone pine in Inner Spain (GORDO, 2004), though the limiting environment sharpened the response.

The objective of the present paper was to elucidate the relevance of genetic and environmental factors for indi- vidual cone yield, cone survival and yield quality in the annual crops of this clone bank, as well as possible trends or changes in time linked to the coming-into-production during its first years. Due to outplanting failures and repeated replanting, the originally complete block design failed to stratify adequately the exogenous diversity of tree development and cone yield. Therefore tree size was evaluated as a yield covariate for an individual cone yield model that estimated the clonal values after correction of environmental biases, in order to rank the tested genotypes.

\section{Methods}

\section{Site description and plant material}

The study was carried out in the Stone pine clone bank B23MN1, located in Quintanilla, at $4^{\circ} 20^{\prime} \mathrm{W}$, $41^{\circ} 35^{\prime} \mathrm{N}$ and $890 \mathrm{~m}$ a.s.l. on the Spanish Inland Plateau. The soil is a shallow terra rossa type over a horizontal limestone rock surface (Rendzic Leptosol). An automatic weather station within the plantation records daily maximum and minimum temperature and rainfall. Average annual temperature was $10.1^{\circ} \mathrm{C}$, and annual rainfall averaged $508 \mathrm{~mm}$ during 1990-2003, but it ranged from 277 to $726 \mathrm{~mm}$ with a very irregular distribution as much between years as between seasons. Occasional frosts occurred until May or June, early frosts from September or October.

The clone bank was established between 1992 and 1993 as part of the Regional Stone Pine Improvement Programme in Castile-Leon. The nursery-raised grafts comprised 98 clones selected for high cone yield in the pine forests of the Northern Inland Plateau provenance region that covers 37,000 ha, i.e. $20 \%$ of the natural Stone pine area in Spain and $6 \%$ of its world area. Ramets had been obtained in 1991 by cleft grafting on seedgrown rootstocks of the same species. Only 585 positions (98 clones) of the originally 1.200 positions in the clone bank (12 ramets of 100 clones) are occupied with 201 trees planted in March 1992, 235 in November 1993 and 149 in November 1993. The spacing is $6 \times 6 \mathrm{~m}$, thus the plantation occupies 4.3 ha within a 8 ha gap in an old Stone pine stand, so lateral pollination guaranteed cone setting since the first flowering. The ramets have not been top-pruned, nor have any other cultural treatments been applied except manual weeding of the tree pits once a spring. Shoot and cone growth and flowering phenology of the plantation have been studied in previous papers (MUTKE et al., 2003a; MUTKE et al., 2005).

\section{Field measurements}

Since 1994, the first nine cone cohorts have been monitored at individual tree level (table 1), registering the number of female conelets before $(I F)$ and after pollination $(F)$ and the cones surviving until first $(N O)$, second (N1) and last winter. During the harvest, the total cone number $(N T)$ and, after eliminating pest-destroyed cones, the final cone yield both in number $(N C)$ and weight $(P C)$ were measured. From the first four cone yields, the seeds of each individual cone were extracted and cleaned, the empty or rotten seeds removed by floatation in water, the sound seeds counted and 
Table 1. - Observations (number of trees) with values greater than zero of successive cone and seed yield parameters of the nine reproductive cohorts (total plot size 586 trees).

\begin{tabular}{|c|c|c|c|c|c|c|c|c|}
\hline \multicolumn{2}{|c|}{ Yield $n / n+1$} & IF & F & No & N1 & NT & NC, PC & PP \\
\hline & year & $\mathrm{n}-2$ & $\mathrm{n}-2$ & $\mathrm{n}-2$ & $n-1$ & n & $\mathbf{n}$ & $\mathbf{n}$ \\
\hline 1 & 1995/96 & - & 13 & 13 & 12 & 11 & 11 & 11 \\
\hline 2 & 1996/97 & - & 120 & - & 119 & 115 & 115 & 115 \\
\hline 3 & $1997 / 98$ & - & 177 & - & 173 & 169 & 169 & 169 \\
\hline 4 & 1998/99 & 320 & 317 & 306 & 296 & 288 & 281 & 281 \\
\hline 5 & 1999/00 & 428 & 356 & 349 & 334 & 333 & 326 & (191) \\
\hline 6 & 2000/01 & 528 & 520 & 516 & 488 & 485 & 484 & (80) \\
\hline 7 & $2001 / 02$ & 553 & 552 & 552 & 528 & 525 & 514 & (41) \\
\hline 8 & $2002 / 03$ & 552 & 551 & 551 & 551 & 352 & 343 & - \\
\hline 9 & 2003/04 & (52) & (52) & (52) & (52) & 451 & 409 & - \\
\hline
\end{tabular}

$I F$ - initial female conelets number; $F$ : number of pollinated, lignified conelets; NO: number of cones surviving the first summer; N1: number of one-year old cones; NT: total number of ripe cones; $N C$ : number of sound cone; $P C$ : cone yield in $\mathrm{kg}$; $P P$ : seed yield in kg; (number in brackets): number of sampled trees for cone survival (cohort 2003/04) and for cone measurement and seed extraction (since 1999).

weighed $(P P)$. Only samples of cones were processed in the next three years and no seed data exist for the last two years. In winter 1999/2000 and 2002/03, stem diameters at ground level and above the graft union of each tree were measured as biometric covariates.

\section{Data analysis}

Consecutive yield variables and sequential transition rates

The distributions and correlations were studied for all yield variables measured along the pathway from the initial female strobili number $(I F)$ to seed lot in $\mathrm{kg}(P P)$ at annual tree yield level (table 1), obtaining the sequential transition rates, i.e. proportion of pollination success $\left(\mathrm{F} / \mathrm{IF}_{\mathrm{F}}\right)$, survival throughout the three years $\left({ }^{N T / F}={ }_{\mathrm{NT}} /{ }_{N 1} *\right.$ $\left.{ }^{N 1 /}{ }_{N O} * N O / F\right)$, proportion of sound cones $(N C / N T)$, mean cone weight $(P C / N C)$ and seed output in weight $(P P / P C)$. Since the transition rates varied widely between years, correlation analyses were performed separately for each cohort. In order to resolve the strongly right-skewed distribution and heteroscedasticity of all yield variables among trees, logarithmic transformations were used, converting the product of multiplicative transition rates for each seed lot (tree $\mathrm{x}$ year)

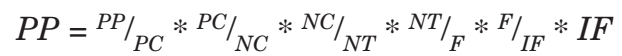

into the sum of additive factors:

$$
\begin{aligned}
& \ln (P P)=\ln (I F)+\ln \left(F /{ }_{I F}\right)+\ln \left(N T /{ }_{F}\right)+ \\
& \ln (N C / N T)+\ln (P C / N C)+\ln (P P / P C
\end{aligned}
$$

The squared correlation coefficient $\mathrm{r}^{2}$ of each (logtransformed) yield variable in the given sequence from female cone bud number $\ln (I F)$, conelets after pollination $\ln (F)=[\ln (F / I F)+\ln (I F)]$ etc. with the final seed yield $\ln (P P)$ gives the proportion of variation of $\ln (P P)$ attributed to each step as difference between its $\mathrm{r}^{2}$ and that of the step before. This $\Delta \mathrm{r}^{2}$ approach is equivalent to the proportion of the total sum of squares of $\ln (P P)$ estimated by sequential Type I Sums of Squares from the ANOVA of the saturated model for $\ln (P P)$ in equation 1 (coefficient of determination $\mathrm{R}^{2} 1.00$, i.e. zero error term).

Degree of genetic determination of the relevant transition rates

General linear models (GLM) were fitted for those transition rates that in the previous analyses resulted to be the most significant for the final seed yield. Models included the year $\left(E_{j}\right)$ and clone $\left(G_{i}\right)$ as additive factors over the overall mean $(m)$ of the response variable $\left(y_{i j}\right)$, assuming an independent, normally distributed residual ( $e_{i j}$ for $i^{\text {th }}$ clone and $j^{\text {th }}$ year):

$$
y_{i j}=m+E_{j}+G_{i}+e_{i j}
$$

In each case, fulfilling of basic assumptions, especially the independence and homogeneity of residual $(e)$ variances and non-significance of clone by year interaction $G x E$ were checked. When reasonable, the additive environment factor year $E$ was substituted by significant rainfall covariates. The clonal effects (model coefficients $G_{i}$ ) multiplied by the (year-adjusted) heritability gave the improvement value or expected genetic gain corresponding to each clone $g_{i}=H^{2} G_{i}$ (FALCONER and MACKAY, 1996).

Size-yield correlation and degree of genetic determination of the cone yield

Finally, a GLM was fitted for individual cone-yield data in order to estimate the heritability of the character and the genetic values of the tested genotypes. An accumulated yield model for the total production of each tree in the first nine years (SNEDECOR and COCHRAN, 1967) was preferred to an analysis of the nine crops as repeated measurements (MEREDITH and STEHMAN, 1991) or adjusting one independent model for each year ( $c f$. MatziRis, 1993; NikKanen and Ruotsalainen, 2000), because the annual yields of a tree were not independent due to the observed geometric upwards trend while the plantation was still coming in production and also to ramet-by-year interactions caused by negative autocorrelations with previous yields of the same tree (MUTKE et al., 2005).

The first principal component $D$ of the stem diameters at ground level and above the graft union of each tree, measured in 2002/03, was used as tree-size covariate. The principal component analysis retained one sole component with eigenvalue above 1.0 that absorbed $98 \%$ of the variation in original variables, characterising the huge size differences between trees (stem diameters at ground level varied from 3.8 to $19.6 \mathrm{~cm}$, average $11.5 \mathrm{~cm})$.

In a preliminary multivariate analysis of variance (MANOVA) for $D$ and the log-transformed accumulated cone yield of the tree $(L N P=\ln (P), P$ in $\mathrm{kg})$ in dependence on the fixed effect of each of the three planting cohort $(o \in\{1,2,3\})$ and random factor genotype $i$ (98 
clones), the phenotypic values of each tree were broken down into three components: (1) the adjusted mean for the planting cohort, (2) the clonal deviation (3) the residual value (environment deviation) of the individual tree (eq. 3).

$$
P_{j(i), o}=m+a_{o}+G_{i}+e_{j(i), o}
$$

where

$P_{j(i), o} \quad$ phenotypic value of ramet $j$, clone $i$, cohort of response variable (size $D$ or yield $L N P$ )

$\mathrm{m}+\mathrm{a}_{0}$ adjusted mean for planting cohort $o$

$G_{i} \quad$ additive effect of clone $i$

$e_{j(i), o} \quad$ residual error in ramet $j$ of clone $i$

The degree of genetic determination was adjusted within the planting cohort $H_{a d j .}^{2}=V G /(V G+V e)$. The phenotypic covariance between tree size and cone production adjusted for planting cohort was partitioned into the genotypic and environmental covariances $\operatorname{cov}_{P}=$ $\operatorname{cov}_{G}+\operatorname{cov}_{E}$ (FALCONER and MACKAY, 1996). Because both were found significant, the finally fitted model for logtransformed cone yield LNP (eq. 4) included, besides the factor clone, two covariables: non-genetic size components obtained by splitting up the size variable $D$ into the cohort mean $\left(D_{o}=m+a_{o}\right)$ and the environmental residuals $\left(D_{e}\right)$ and dropping the clonal deviation $\left(D_{G}\right)$. The cohort mean size $D_{o}$ was introduced instead of the additive effect of outplanting cohort on LNP because they presented a coefficient of correlation $\mathrm{r} 1.00$ (differences between cohorts mean yields were explicated by their different mean tree size). Fulfilling of residuals' normality, independence and homoscedasticity were checked graphically.

$$
L N P_{j(i), o}=m+a D_{o}+b D e_{j(i), o}+G_{i}+e_{j(i), o}
$$

where

$$
\begin{array}{ll}
L N P_{j(i), o}=\ln \left(\operatorname{Pr}_{j(i), 0+1)}\right. & \text { log-transformed accumulated } \\
& \text { cone yield }[\mathrm{kg}] \text { of ramet } j, \text { clone } i \\
m & \text { grand mean } \\
a & \text { linear effect of the cohort mean } \\
& \text { tree size } D_{o} \\
& \text { linear effect of residual tree size } \\
& \text { deviation } D e_{j(i), o} \\
& \text { additive effect of clone } i \\
G_{i} & \text { residual variation in ramet } j \text { of } \\
e_{i j} & \text { clone } i .
\end{array}
$$

\section{Results}

The first incipient cone yield (twelve cones in all) of the studied clone bank occurred five years after grafting, four after planting. Since then, production has increased with a geometric trend $\left(\mathrm{R}^{2}=0.74\right)$ that at ten years surpassed $1 \mathrm{~kg} /$ tree, i.e. $0.16 \mathrm{~kg}$ seeds (fig. 1), though with a strong right-skewed distribution among trees. The 2003/04 crop amounted to $963 \mathrm{~kg}$ of cones (mean yield $=1.6 \mathrm{~kg} /$ tree), though the upper $10 \%$ of the trees yielded $38 \%$ of total yield ( $369 \mathrm{~kg}$, mean $=6.4 \mathrm{~kg} /$ tree $)$ and the most productive ten trees (less than $2 \%$ of the orchard) produced $9 \%$ of total yield (mean $=9.0 \mathrm{~kg} /$ tree) . On the other hand, 18 smaller trees remained without any ripe cones since grafting.

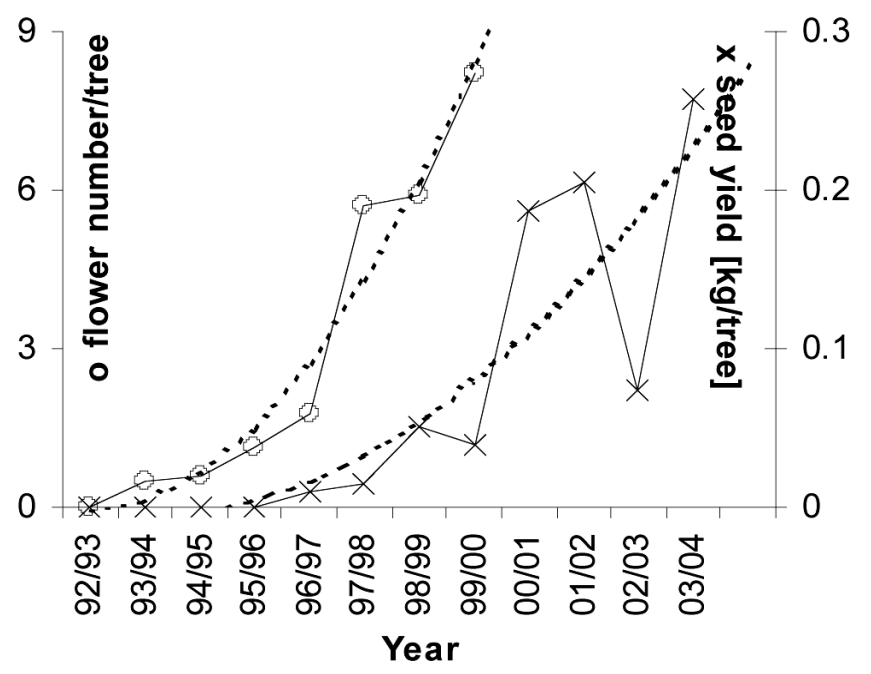

Figure 1. - Average individual flower number (o) and seed yield (x) (--- quadratic trends).

\section{Cone survival}

The consecutive yield variables at tree level along the pathway from number of initial female buds $I F$ up to the cone and seed yield in weight $(P C, P P)$ were positively correlated in all years (since 1997/98 all $r>0.65$ ); thus only the first one, the last two and the sequential transition rates between them are presented here (fig. 2). Both initial strobili number and final yield shot up after the fifth cohort (yield 2000/01), though the latter variable presented a higher annual variability around its geometric trend than the first one (fig. 1), due to varying cone survival rates, cone size and seed output (fig. 2). There was no difference in the annual pattern of the transition rates between the three outplanting cohorts.

The consequences of two meteorological events on cone survival must be stressed. First, after the unusually warm early spring 1997, that had moved forward phenology by several weeks in comparison to other years, a late frost in May damaged female conelets, aborting $25 \%$ of the cohort before cone setting (yield 1999/2000), whereas in the other years, pollination success was always above $95 \%$. Second, during the unusually harsh December 2001 (minimum $-18^{\circ} \mathrm{C}$ ), $45 \%$ of the new conelets and $53 \%$ of the one-year-old cones aborted (yield 2002/03 and 2003/4, respectively). Apart from the effects of these two singular events, the survival rate from pollinated conelets $F$ to first and second year cone counts NO, N1 and mature cones NT was 80-92\% (fig. 3).

The proportion of sound cones in the yield $N C / N T$ reflected the incidence of cone pests, mainly the larvae of the moth Dioryctria mendacella Stgr.. Until 2002/03, less than $10 \%$ of the annual crop was infested, but attack rose to $29 \%$ in $2003 / 04$. Incidentally it was the worst yield for the last ten years in the surrounding Stone pine forests, suggesting that the higher infestation level was due to the pest concentrated locally in the plantation, attracted by its abundant cone yield.

\section{Cone size}

The mean cone weight $P C / N C$ showed higher annual variability than the other transition rates (fig. 2). Espe- 

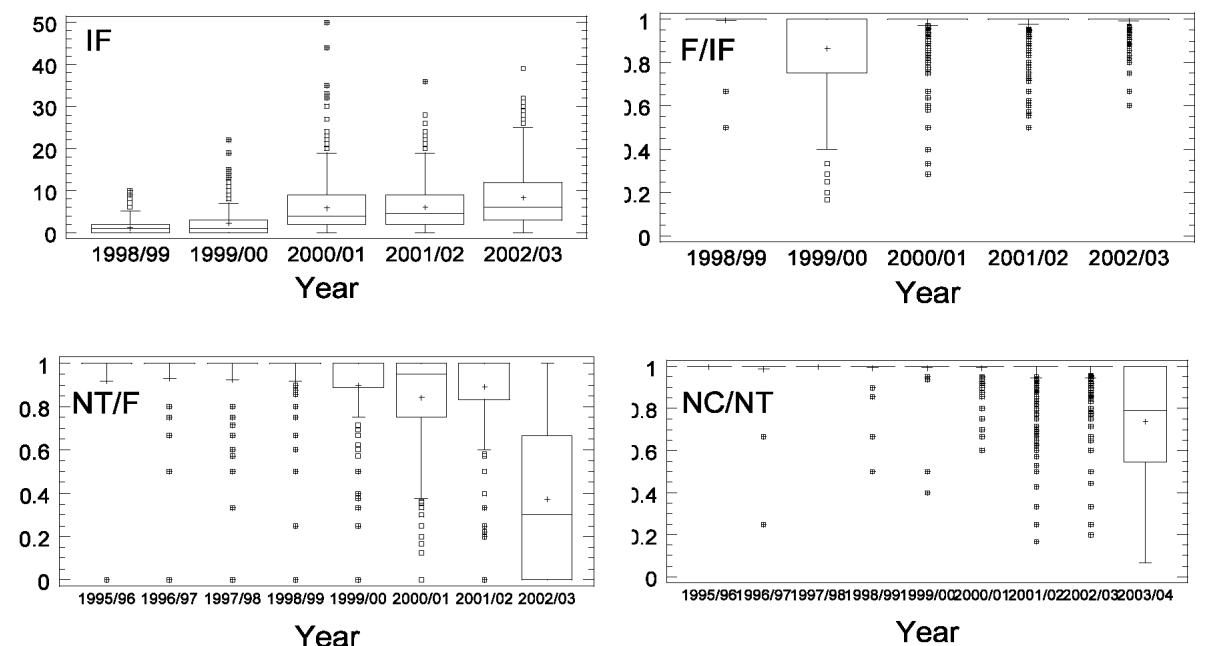

Year

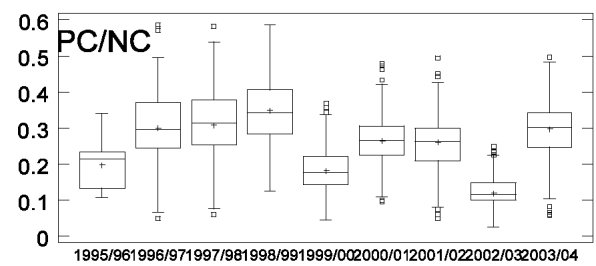

Year
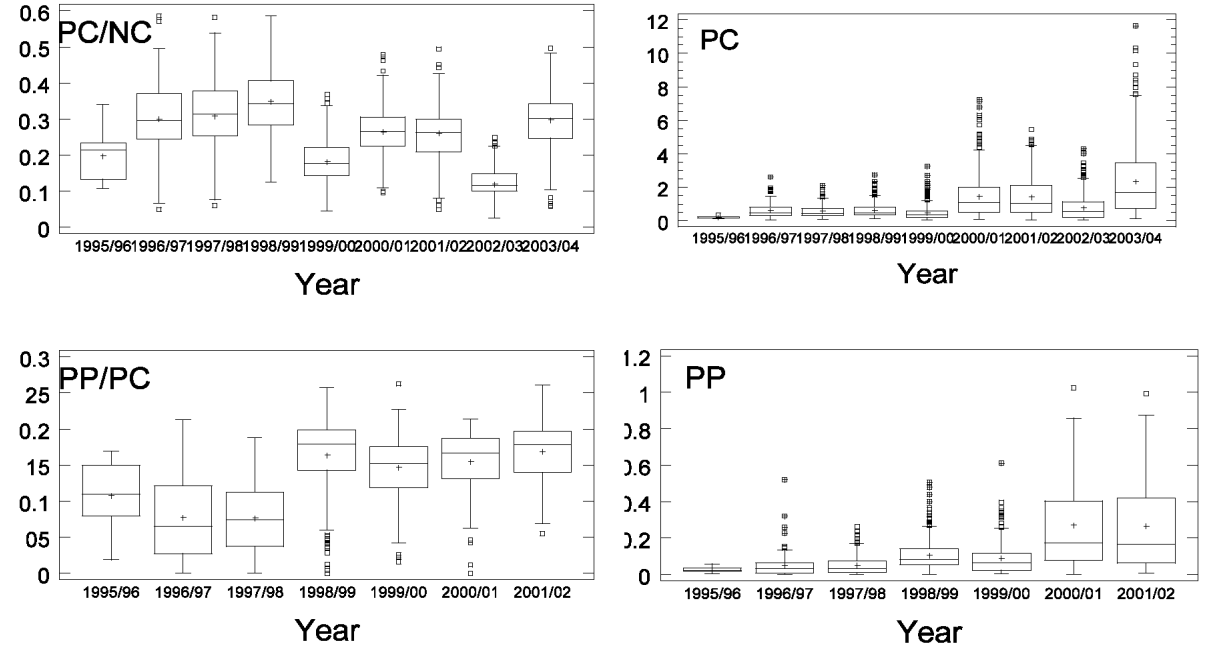

Figure 2. - Box-and-whisker-plots of yield variables and transition rates at tree level by cohorts ( $I F$ - initial female conelets number; $F$ - number of pollinated, lignified conelets; $N O$ - number of cones surviving the first summer; $N 1$ - number of one-year old cones; $N T$ - total number of ripe cones; $N C$ - number of sound cone; $P C$ - cone yield in $\mathrm{kg}$; $P P$ - seed yield in $\mathrm{kg}$ ( $P P$ since cohort 1999/2000 only in sample trees).

cially three crops stood out because of their reduced cone size. The reduced size of the twelve cones comprising the first crop (mean weight $=192 \mathrm{~g}$ ) might have been caused by outplanting stress, but the meager cones in 1999/00 ( mean $=183 \mathrm{~g})$ and particularly in 2002/03 (mean =129 g) indicate a direct relation to water stress (fig. 4): annual mean cone weight and rainfall amount from September to August of the last year of cone ripening $P_{a}$ were strongly correlated $(\mathrm{r}=0.91)$.

On the other hand, cone weight $P C / N C$ presented in some years a weak but significant negative correlation with the cone number of the tree $(r>-0.15)$. Nevertheless the overall correlation between mean cone weight and cone yield in $\mathrm{kg}$ was positive $(\mathrm{r}=0.17-0.33$ in all years). Also mean seed weight showed significant phenotypic correlation with cone weight $(\mathrm{r}=0.52-0.84)$ and was correlated weakly but significantly with seed yield $P P(\mathrm{r}=0.10-0.35)$.

\section{Seed output}

In the first three crops an abnormally low output of sound seeds $(P P / P C$, in $\mathrm{kg}$ per $\mathrm{kg}$ of cones) was observed,

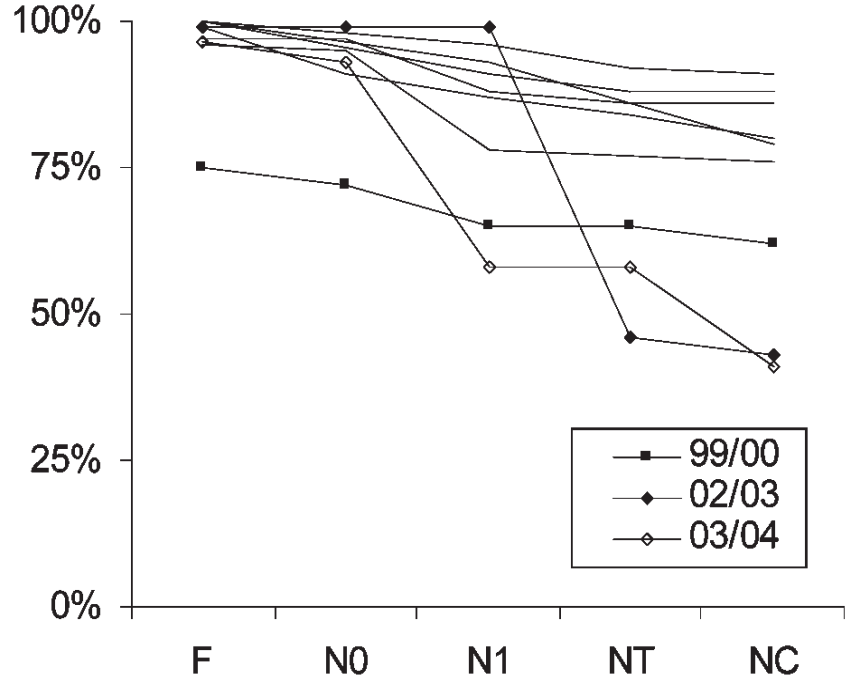

Figure 3. - Survival of 9 cone cohorts from initial formed female conelets $(100 \%)$ to pollinated conelets $F$, conelets after first (NO) and second summer (N1), mature cones (NT) and sound cones $(N C)$. Only cohorts with survival rate less than 0.8 due to frost losses are identified. 


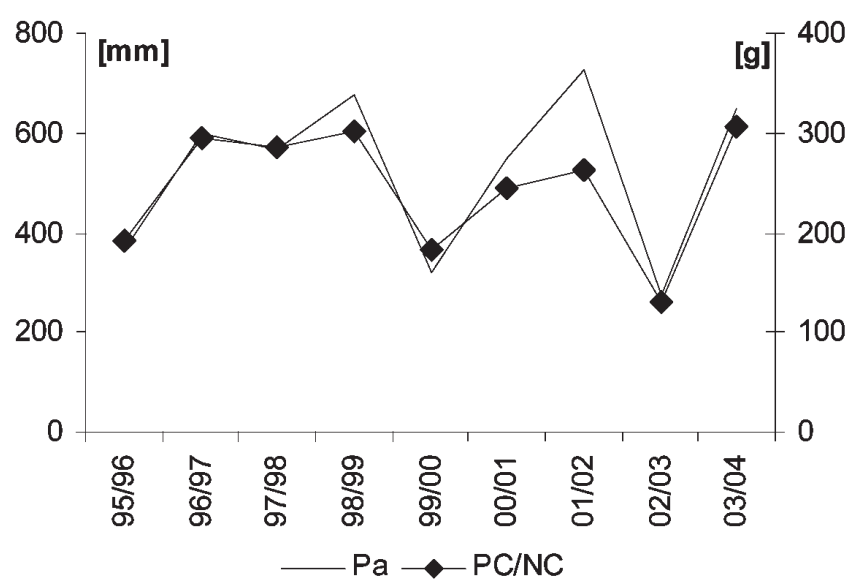

Figure 4. - Annual mean cone weight $P C / N C[\mathrm{~g}]$ and rainfall during the last year (Sept.-Aug.) of cone development $\mathrm{Pa}$ [mm].

a phenomenon correlated directly with the low proportion of sound seeds in the total seed number of the cone (coefficient of correlation at cone level $r=0.83$ ). No correlation with annual meteorology was found. As the phenomenon might be due to post-planting stress, these three initial crops were excluded from the following analysis of variance. Since 1998/99, the seed output $(P P / P C)$ presented stable means expected for the species (15-18\%), though in all years a few cones were found that had more than $50 \%$ empty seeds (i.e. seed outputs below $10 \%$ or even $5 \%$ of cone weight).

\section{Influence of each transition rate on final seed yield variation}

The relevance $\left(\Delta R^{2}\right)$ of each transition between initial flower number and final seed yield for the annual yield of each tree and the changes in time is reflected by its sequential sum of squares (SS type I) of the saturated additive model for the log-transformed seed yield $\ln (P P)$ (eq. 1). During the observed years, the number of conelets $(I F, F)$ greatly increased both its mean value and its variance between trees, and so did the relevance of this factor for the individual seed yield differences $\left(\mathrm{R}^{2}\right.$ grew from 0.17 to 0.74$)$. On the other hand, once the average seed output $(P P / P C)$ stabilised after the abnormal first years, its impact on seed yield diminished to less than 0.15 of total variation (fig. 5). In all years, more than $90 \%$ of the variation of final seed yield was determined by the initial conelet number $I F$ and the two most variable transition rates, mean cone size $P C / N C$ and seed output $P P / P C$. In contrast, the influence of variations in the transition rates from flowers to cone number was minor, excepting singular events like the previously mentioned frost damages.

\section{Degree of genetic determination of the cone size,} seed output and seed size

The phenotypic variances at tree yield scale for mean cone weight $(P C / N C)$, seed output as proportion of cone weight $(P P / P C)$ and mean seed weight $(P P / N P)$ were split into genetic and environment variances after adjusting for the variation between years (eq. 2). However, no regression model was established for the successive cone survival rates along the pathway from flowers

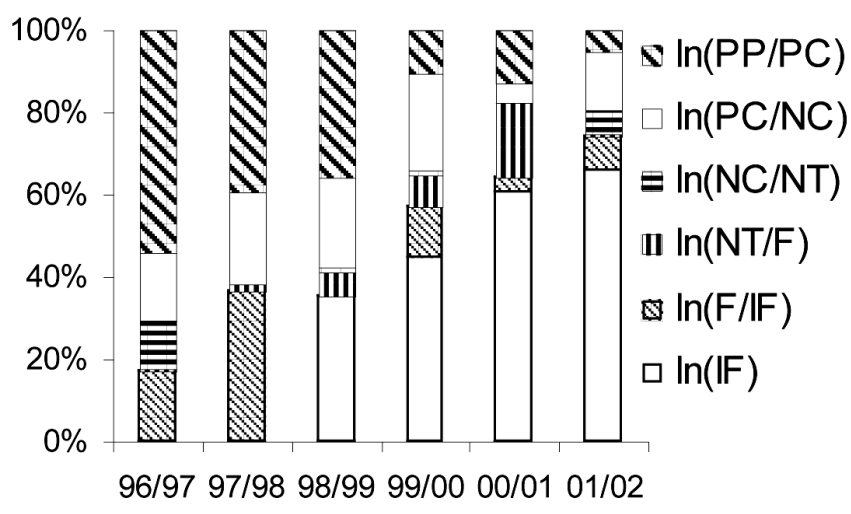

Figure 5. - Coefficients of determination (sum of Type I SS) for the saturated additive model for $\ln (P P)$ (eq. 1). No initial conelet number $I F$ was registered for the first yields, thus the effects of the first two steps are pooled in these years. Yield $1995 / 96(n=12)$ is not represented (Variable names see legend table 1 or fig. 2).

$F$ to sound cones $N C$, because these steps had shown minor overall influence on final cone yield variation and were determined by different factors each year, even by Poisson (threshold) processes like extreme frost occurrence.

For cone weight $(P C / N C)$, genetic variance contributed $17 \%$ of the adjusted phenotypic variance (degree of genetic determination $H_{a d j .}^{2}=V_{G} / V_{p} a d j$.), after adjusting the between-year differences (factor $E_{j}$ ) that accounted for $R^{2}=47 \%$ of overall phenotypic variation (whole model $\mathrm{R}^{2}=0.58$; eq. 2 ). Since as much as $83 \%$ of this annual variation in mean cone weight was attributable to rainfall, an alternative model was adjusted with two rainfall sums instead of the additive effect $E$ : firstly the rainfall of the last year (September to August) of cone development $P_{a}$ accounted for $34 \%$ of total cone size variance at annual tree level, and secondly the rainfall during the three months of main cone growth May to July $(P m j j)$ for additional 6\%, without changing the sum of squares attributed to $G$ and only changing slightly its estimate for each clone (whole model $R^{2}=0.51$; eq. 5) and for $H_{\text {adj. }}^{2}(15 \%)$.

$$
\begin{aligned}
& P C / N C_{i j}=\left(18.8 \mathrm{~g}+0.305 P a_{j} g m^{-1}+\right. \\
& \left.0.687 \mathrm{Pmjj}_{j} g \mathrm{~mm}^{-1}\right)+G_{i}+e_{i j}
\end{aligned}
$$

There was no significant genotype by environment correlation, nor interaction GxE, GxPaf or GxPmjj in any of the models. The regression coefficients indicate that the mean cone weight incremented about $0.3 \mathrm{~g}$ per millimetre of additional rainfall in the last year of cone growth (even $1 \mathrm{~g} \mathrm{~mm}^{-1}$ for rain between May and July).

Seed output as proportion of cone weight $(P P / P C)$ was analysed only in cohorts $1998 / 99$ to $2001 / 02$, excluding the initial yields with abnormally low seed output. Genetic variance explained $20 \%\left(\mathrm{H}^{2}\right.$ adj. $)$ of the phenotypic variance after adjusting for differences between years (eq. $2, \mathrm{R}^{2}=0.31$ ). Most variation remained as residual, due to the erratic presence of single cones with very low seed output. There was no significant influence of tree size, spatial autocorrelation or genotype by year interaction on the seed output either. Similarly, the same model (eq. 2) accounted for $\mathrm{R}^{2}=47 \%$ of phenotypic seed size 
$(P P / N P)$ variation, the degree of genetic determination $\mathrm{H}^{2}$ adj. was $20 \%$ after year adjustment.

\section{Size-yield correlation and degree of genetic determination of the cone yield}

The MANOVA for tree size variable $D$ and yield variable $(L N P)$ showed a significant multivariate influence of both outplanting cohort (Wilk's lambda 0.40) and genotype (Wilk's lambda 0.37). The squared correlation coefficient $\mathrm{r}^{2}$ with the phenotypic value of $D$ was 0.50 for mean size of the outplanting cohort $D_{o}$ and 0.17 for the clonal deviation $D_{g}$. The $\mathrm{r}^{2}$ values between phenotypic yield value $(L N P)$ and its cohort mean and clonal deviation was 0.43 and 0.17 , respectively. Therefore, the squared correlation coefficient between genetic and cohort-adjusted phenotypic values was $\mathrm{r}_{\text {adj. }}^{2}=0.34$ for tree size $\left(\mathrm{H}^{2}{ }_{\text {adj. }}=21 \%\right)$ and 0.29 for cone yield $\left(\mathrm{H}^{2}{ }_{\text {adj. }}=15 \%\right)$ ignoring size-yield correlations. But phenotypic covariance between size and yield variable was 0.99 (correlation $r_{P}=0.88$ ), between size and yield variables adjusted for cohort mean 0.47 , of which 0.13 was genetic $\left(r_{G}=0.68\right)$ and 0.34 environment covariance $\left(r_{E}=0.83\right)$ (table 2).

Given the perfect correlation between cohort means of size and yield, only the first was used as covariate in the general linear model for $L N P$ (eq. 4). The model's $\mathrm{R}^{2}$ was $87.4 \%$ for the overall $L N P$, mainly determined by the huge size differences between trees (both between and within the three outplanting cohorts) that determined $\mathrm{R}^{2}=71 \%$ for unadjusted value of the individual cone yield variable (fig. 6). Genotypes' sums of squares determined only $\Delta \mathrm{R}^{2}=17 \%$ of unadjusted yield, but as much as $\mathrm{R}_{\text {adj. }}^{2}=57 \%$ of the yield once adjusted for non-genetic size covariates (cohort mean size and individual size deviation) (table 3). The linear effects on yield (i.e.

Table 2. - Phenotypic, genetic and environmental variances (diagonal), covariances (below diagonal) and correlations (above diagonal) of tree size and cone yield variables.

\begin{tabular}{|c|c|c|c|c|c|c|c|c|}
\hline $\operatorname{cov} \backslash r$ & $D_{o}$ & $D_{g}$ & $D_{e}$ & $D$ & $L N P_{o}$ & $L N P_{g}$ & $L N P_{e}$ & $L N P$ \\
\hline$\overline{D_{o}}$ & 0.984 & & & 0.708 & 1.000 & & & 0.654 \\
\hline$D_{g}$ & & 0.336 & & 0.414 & & 0.677 & & 0.276 \\
\hline$D_{e}$ & & & 0.646 & 0.573 & & & 0.831 & 0.530 \\
\hline$D$ & 0.984 & 0.336 & 0.646 & 1.966 & 0.707 & 0.280 & 0.476 & 0.880 \\
\hline$\overline{L N P_{o}}$ & 0.522 & & & 0.522 & 0.277 & & & 0.654 \\
\hline$L N P_{g}$ & & 0.129 & & 0.129 & & 0.107 & & 0.407 \\
\hline$L N P_{e}$ & & & 0.342 & 0.342 & & & 0.263 & 0.638 \\
\hline$L N P$ & 0.522 & 0.129 & 0.342 & 0.993 & 0.277 & 0.107 & 0.263 & 0.648 \\
\hline
\end{tabular}

$D_{o}$ - cohort mean tree size; $D_{g}-$ genetic deviation of tree size; $D^{o}$ - environment (residual) variation of tree size; $\mathrm{D}=$ $\left(D_{o}+D_{g}+D_{e}\right)-$ tree size variable; $L N P_{o}-$ cohort mean cone yield; $L^{g} N P_{g}$ - additive genetic effect on cone yield; $L N P_{e}-$ environment ${ }^{g}$ (residual) variation of cone yield; ${ }^{e}$ LNP = $\left(L N P_{o}+L N P_{g}+L N P_{e}\right)-$ log-transformed cone yield; empty cells: covariance and correlation below 0.0001 (non significant); all other cells $\mathrm{p}<0.001$. regression coefficients $a$ and $b$ eq. 4) of both non-genetic size covariables, cohort mean size $D_{o}$ and individual deviation $D_{E}$, did not differ significantly from each other.

The averaged expected genetic gain in log-transformed cone yield $\left(H^{2}{ }_{a d j}, G_{i}\right)$ ranged from -0.111 to 0.152 , averaging the best ten clones 0.093. Back-transforma-

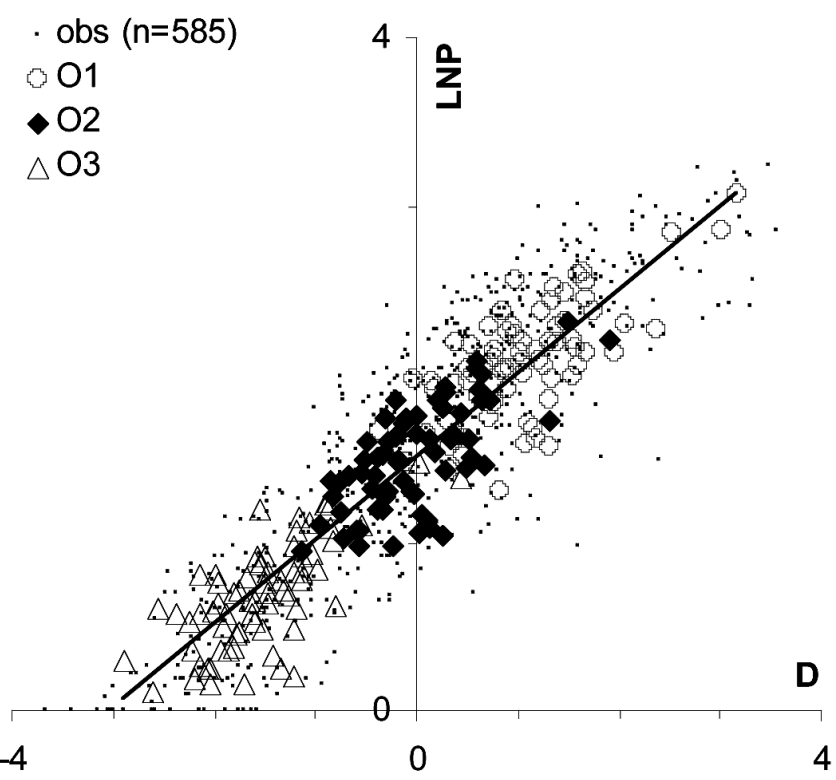

Figure 6. - Scatter plot of the log-transformed cone yield $L N P$ against the size covariate $D$ in 585 grafted Stone pines, coefficient of correlation $\mathrm{r} 0.88$ (O1-3: adjusted clonal mean values for three outplanting cohorts).

Table 3. - Analysis of variance for the log-transformed individual cone yield (sum of 9 crops).

\begin{tabular}{lcccc}
\hline Source of variance & Type I SS & d.f. & MS & F-value \\
\hline $\mathrm{D}_{\mathrm{o}}$ (cohort mean size) & 161.7 & 1 & 161.74 & $1,644^{* * *}$ \\
$\mathrm{D}_{\mathrm{e}}$ (residual size deviation) & 106.1 & 1 & 106.07 & $1,078 * * *$ \\
$\mathrm{G}_{\mathrm{i}}$ (clonal effect) & 62.6 & 97 & 0.65 & $6.56 * * *$ \\
Residuals & 47.7 & 485 & 0.10 & \\
\hline Total & $\mathbf{3 7 8 . 2}$ & $\mathbf{5 8 4}$ & & $\mathbf{R}^{2} \mathbf{8 7 \%}$ \\
\hline
\end{tabular}

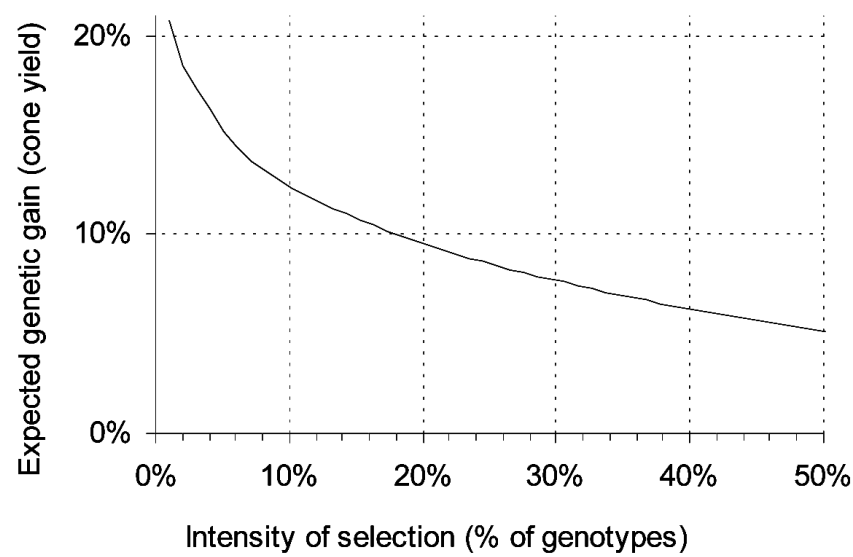

Figure 7. - Expected genetic gain by selecting the best performing of the 98 tested clones. 
tion to raw-data scale would give an overall mean of 3.8 $\mathrm{kg} /$ tree (i.e. the geometric mean of the measured raw data) and estimations for response to selection from $-13 \%(-0.5 \mathrm{~kg} /$ tree for the least productive clone) to $+21 \%$ ( $+0.8 \mathrm{~kg} /$ tree for the most productive clone). The genetic gain obtained by selecting the top $10 \%$ (ten clones out of 98 ) would be $+12 \%(+0.5 \mathrm{~kg} /$ tree) (fig. 7$)$.

\section{Discussion}

The results reflect some interesting aspects of the biological and meteorological processes implied in the Stone-pine cone development. Though the cone crop registered in the first yields was still modest, mean annual yield of the grafted trees since 2000/01 (309 kg ha-1 $\mathrm{yr}^{-1}$ with $6 \times 6 \mathrm{~m}$ setting) was already higher than the average of the surrounding forest in the same period $(235 \mathrm{~kg}$ $\left.\mathrm{ha}^{-1} \mathrm{yr}^{-1}\right)$. Both the situation of the studied clonal orchard in a shallow stony highland soil rather than agricultural land and the lack of early cultural treatments produced a delay and a strong heterogeneity in the vegetative development of the grafted trees, a rather common problem in the practice of traditional forest seed orchards (SMith and Stanley, 1969; Giertych, 1987; Nikkanen and Velling, 1987; Smith, 1987). The extreme environment of the studied plantation at the altitudinal/northern limit of natural Stone pine growth area also shaped the response of the trees on the main limiting factors, i.e. low water availability and occasional excessive frosts, similar to stronger weather-tracking masting habits at the northern limits in other pine species (Despland and Houle, 1997; Sutton et al., 2002).

Due to these environmental restrictions in the studied clone bank, tree size determined as much as $71 \%$ of cone yield $\left(\mathrm{r}^{2}\right)$. The mean stem diameter of the most productive ten trees (out of 585) surpassed their planting cohort's average in $25 \%$, but only four of them were ramets from the most productive ten clones. Their accumulated mean cone yield was $21 \mathrm{~kg}$, nearly the 2.5 -fold average of their planting cohort; the cones harvested only from these ten trees in 2003/04 would correspond to a hypothetical yield above $2,000 \mathrm{~kg}$ per hectare in a $6 \times 6 \mathrm{~m}$ setting. This extrapolation may indicate the strong potential for improving crop yield not only by genetic selection, but primarily by eliminating environmental drawbacks by site selection and cultivation techniques. Actually, in several other Stone pine plantations located on farmland at lower altitudes (with less water stress and frost occurrences), both the crown development and the cone production is more vigorous and homogeneous than in the highland plantation studied here (unpublished data).

Because of the strong environmental variance the estimated degree of genetic determination for additive effects at logarithmic scale was moderate $\left(\mathrm{H}^{2}=0.15\right)$, although the selection potential was actually higher because the genetic effect was multiplicative (rightskewed) on raw-data scale ( $c f$. Bland and Altman, 1996). A similar degree of genetic determination for logscaled cone productivity $\left(\mathrm{H}^{2}=0.18\right)$ was found in another Stone-pine clone bank at nine years (MUTKE et al., 2003b). Genetic correlations of cone yield with mean cone weight, seed output and seed weight were found to be weak but significantly positive $(r=0.27,0.38$ and 0.17 , respectively). The fact that no trade-off between yield quantity and quality traits was observed allows the combination of selection criteria, e.g. excluding from the selection of the most productive genotypes those clones with significantly smaller-than-average genetic values for cone or seed size or seed output. On the other hand, for constructing a selection index it would be necessary to assign an economic relevance for each trait as a weighting coefficient, information that is not available for Stone pine.

In spite of the difficulties and limitations, the analysis of cone yields has shown the presence of genetic variability that allows the definition of the most valuable genotypes captured from prospecting the natural populations of the species. The future results of the more recent experimental plots, installed as farm-field tests in less limiting environment conditions and with extensive site management, may characterise more precisely the tested genotypes of the collection Northern Inland Plateau, as well as clones obtained by selection in the other Spanish provenance regions, under realistic crop conditions.

\section{Acknowledgements}

This study has been carried out within the frame of the Genetic Improvement Programme of Pinus pinea funded by the regional government of Castile-Leon. We grateful acknowledge M. DEL Río and two anonymous reviewers for their thorough and helpful review of the manuscript and J. Climent, R. AlíA and R. CALAMA for valuable comments. SM's contribution was supported by a FPU scholarship from MEC (Spanish Ministry of Education and Science).

\section{References}

BADAL, E. (2001): La recolección de piñas durante la prehistoria en la Cueva de Nerja (Málaga), pp. 101-104 in De neandertales a cromañones - el inicio del poblamiento humano en las tierras valencianas, edited by $\mathrm{V}$. VILLAVERDE, Universidad de Valencia, Valencia.

Bland, J. M. and D. G. Altman (1996): Statistics Notes: Transforming data. Brit. Med. J. 312: 770.

Candela, J. A. and R. Alía (2000): Clonal banks of Pinus pinea, pp. 49-50 in Report of International Field Trip Meeting Mediterranean Silviculture with Emphasis on Quercus suber, Pinus pinea and Eucalyptus sp., IUFRO Working Group 1.05.14, Seville, Spain, May 15-19, 2000.

Catalán, G. (1998): Current Situation and Prospects of the Stone pine as Nut Producer. FAO - Nucis-Newslett. 7: $28-32$

ChAlupKa, W. (ed.) (1987): Flowering and seed-bearing in forest seed orchards. Forest. Ecol. Manag. 19 (Special Issue).

Despland, E. and G. Houle (1997): Climate influences on growth and reproduction of Pinus banksiana (Pinaceae) at the limit of the species distribution in eastern North America. Am. J. Bot. 84: 928-937.

FALCONER, D. S. and T. F. C. MACKAY (1996): Introduction to Quantitative Genetics, $4^{\text {th }}$ Ed. Prentice Hall, Harlow. 
GieRTyCh, M. (1987): Seed orchards in crisis. Forest. Ecol. Manag. 19: 1-7.

GIL, L. (1999): La transformación histórica del paisaje: la permanencia y la extinción local del pino piñonero, pp. 151-185 in Los montes y su historia - una perspectiva política, económica y social, edited by MARín, F., DOMINGO, J., CAlZAdo, A., Universidad de Huelva, Huelva.

Gordo, J. (2004): Selección de grandes productores de fruto de Pinus pinea en la Meseta Norte. Ph. D. Thesis, Universidad Politécnica de Madrid, Madrid.

KJÆR, E. D. and H. WELLENDORF (1997): Variation in Flowering and Reproductive Success in a Danish Picea abies (Karst.) Seed Orchard. Forest Genet. 4(4): 181-188.

LANNER, R. M. (1981): The Piñon Pine - A Natural and Cultural History. University of Nevada Press, Reno, USA.

Magini, E. and R. Giannini (1971): Prime osservazioni sulla produzione di strobili e semi di un parco di cloni di pino domestico (Pinus pinea L.). L'Italia Forestale e Montana XXVI(2): 63-78.

MATZIRIS, D. (1993): Variation in cone production in a clonal seed orchard of black pine. Silvae Genet 42(2-3): 136-141.

Meredith, M. P. and S. V. Stehman (1991): Repeated measures experiments in forestry: focus on analysis of response curves. Can. J. For. Res. 21: 957-965.

Mutke, S., J. Gordo and L. GIL (2000): The Stone Pine (Pinus pinea L.) Breeding Programme in Castile-Leon (Central Spain). FAO Nucis-Newslett. 9: 50-55.

Mutke, S., J. Gordo, J. Climent and L. GiL (2003a): Shoot Growth and Phenology Modelling of Grafted Stone Pine (Pinus pinea L.) in Inner Spain. Ann. For. Sci. 60(6): 527-537.

Mutke, S., B. SadA, S. Iglesias and L. Gil (2003b): Evaluación de la producción individual de piña en un banco clonal de pino piñonero (Pinus pinea L.) en Madrid. Invest. Agr.: Sist. y Recur. For. 12(1): 149-157.
Mutke, S., R. Sievänen, E. NikinmaA, J. Perttunen and L. GIL (2005): Crown architecture of grafted Stone pine (Pinus pinea L.): shoot growth and bud differentiation. Trees 19(1): 15-25.

NikkANEN, T. and P. Velling (1987): Correlations Between Flowering and Some Vegetative Characteristics of Grafts of Pinus sylvestris L. For. Ecol. Manag. 19: $35-40$.

Nikkanen, T. and S. Ruotsalainen (2000): Variation in flower abundance and its impact on the genetic diversity of the seed crop in a Norway spruce seed orchard. Silva Fenn. 34(3): 205-222.

Prada, M. A., J. Gordo, J. De Miguel, S. Mutke, G. Catalán, S. Iglesias and L. Gil (1997): Las regiones de procedencia de Pinus pinea L. en España. MAPA, Madrid.

Smith, W. H. and R. G. Stanley (1969): Cone Distribution in Crowns of Slash Pine (P. elliottii Engelm.) in Relation to Stem, Crown and Wood Increment. Silvae Genet. 18: 86-91.

Smith, R. F. (1987): The effects of fertilization on flowering of various-sized Black spruce (Picea mariana) trees. For. Ecol. Manag. 19: 189.

SNEDECOR, G. W. and W. G. CochraN (1967): Statistical Methods. Iowa State Univ. Press, Ames.

Sutton, A., R. J. Staniforth and J. TARDif (2002): Reproductive ecology and allometry of red pine (Pinus resinosa) at the northwestern limit of its distribution range in Manitoba, Canada. Can. J. Bot. 80: 482-493.

Thirgood, J.V. (1981): Man and the Mediterranean Forest. A history of resource depletion. Academic Press, London.

WolfF, R. L. and C. C. BAYARD (1995): Fatty acid composition of some pine seed oils. J. Am. Oil Chem. Soc. 72: 1043-1046.

\title{
Conservation Approaches For Autochthonous Woody Plants in Flanders
}

\author{
By K. VANDER MijnsbrugGe ${ }^{1,2)}$, K. CoX ${ }^{1)}$ and J. VAN SLYCKeN ${ }^{1)}$
}

(Received 19 ${ }^{\text {th }}$ April 2005)

\begin{abstract}
Autochthonous genetic resources of woody plants have become seriously endangered in Flanders because of the particularly low and fragmented forest cover, centuries of intensive forest use in this highly populated area and the wide-spread usage of non-autochthonous planting stock in reforestation and landscape plantings. Intraspe-

1) Institute for Forestry and Game Management, Gaverstraat 4, B-9500 Geraardsbergen, Belgium.

2) Corresponding author: kristine.vandermijnsbrugge@inbo.be, Tel: 3254437146 , Fax: 3254436160 .
\end{abstract}

cific hybridisation between remnant autochthonous populations and foreign genotypes, which can show inadequate adaptation, may influence the autochthonous genetic constitution and fitness in the long term. As several European countries face similar problems, the objective of this paper is to outline the conservation measures that are taken in Flanders. The central aim is to maintain and create the necessary conditions for natural and flexible evolution of the genetic diversity of autochthonous trees and shrubs. An inventory survey to locate remaining autochthonous populations was started in 1997 and will be completed in 2006. Relict populations are preserved in clonal banks. Central issues are 